\title{
Microflora of the polar bear (Ursus maritimus) from natural population of the Russian Arctic
}

\author{
Tatyana Denisenko ${ }^{1, *}$, Andrey Boltunov², and Stanislav Belikov ${ }^{3}$ \\ ${ }^{1}$ Moscow State Academy of Veterinary Medicine and Biotechnology - MVA named after K.I. \\ Scryabin, Moscow, Russia \\ ${ }^{2}$ Marine Mammals Scientific Expeditionary Center, Moscow, Russia \\ ${ }^{3}$ All-Russian Scientific Research Institute of Ecology, Moscow, Russia
}

\begin{abstract}
The paper presents the results of studying the microflora of the polar bear (Ursus maritimus) organism. Samples from 22 individuals were collected during three comprehensive scientific expeditions arranged in 2014 and 2015 at the request of PJSC Rosneft Oil Company. Based on the results of laboratory processing of the samples obtained, for the first time in the Russian history of studying the species, the species and quantitative composition of microorganisms in the oral cavity and conjunctiva of the polar bear's eye was assessed. From the mucous membrane materials of the studied polar bear individuals, 91 isolates of microorganisms were obtained and identified up to 23 genera and species. These microorganisms were represented by both bacteria and microscopic fungi. Pathogenicity factors of the isolated microflora were determined: hemolytic properties, presence of plasma coagulase and lecithinase enzymes, virulence. The antibiotic resistance of the isolated microflora was assessed. The data obtained in the course of microbiological studies will not only help to determine the health status of the studied animals but can also be used in the future as one of the components of a comprehensive monitoring of the state of Arctic marine ecosystems.
\end{abstract}

\section{Introduction}

This paper presents the first results of a study of the microflora of the polar bear (Ursus maritimus), carried out as part of a comprehensive study of the species in areas of prospective hydrocarbon development on the Russian Arctic shelf in order to develop effective measures to preserve the polar bear in a changing climate and growing economic development of the Arctic region.

The polar bear is one of 5 mammal species included in the list of flora and fauna species that are indicators of the sustainable state of marine ecosystems in the Arctic zone of the Russian Federation [5]. It is assumed that changes in the state of the indicator species in one way or another reflect processes in the ecosystems of which this species is a part. In this regard, a detailed study of an integrated approach to the study of those parameters of the indicator species' well-being that can ensure fulfillment of the monitoring tasks of the Arctic

\footnotetext{
*Corresponding author: denisenkote@yandex.ru
} 
marine ecosystems, becomes especially urgent. One of these parameters may be the state of the polar bear's microflora.

As the primary predator of the Arctic marine ecosystem, the polar bear is at the top of the food chain. Since the end links of the trophic chain, as a rule, accumulate and concentrate xenobiotics, and can also receive various pathogens from other food levels, the predator's body serves as an indicator of the ecological and epizootic state of the entire ecosystem [2]. В условиях физиологической нормы организм взрослых особей животных содержит сотни видов различных микроорганизмов. Under conditions of a physiological norm, the body of adult animals contains hundreds of species of various microorganisms. The composition of microbial associations of an animal's body directly depends on its physiological state, therefore, it can serve as a criterion for assessing the health of both an individual and the population as a whole [3, 4].

Until now, practically no attention has been paid to microflora research in the world practice of studying polar bears. There are only a few publications on the study of microflora in a small number of excrement samples of this predator and bacteriological smears from the anus $[5,6]$. According to these publications, the microflora of the large intestine of the polar bear is represented by a significantly lower species diversity of microorganisms compared to other mammalian species, including predators, and is represented by almost $70 \%$ bacteria of the genus Clostridium. At the same time, the authors studied only the species composition of microorganisms in animal feces by means of genetic analysis of the material and cultural methods. However, information on the biological properties of bacteria isolated from polar bears has not been described in the scientific literature. There is also no data on the species and quantitative characteristics of the microflora of the respiratory tract, reproductive system, conjunctiva of the eye and the upper gastrointestinal tract.

The emergence and course of infectious pathologies depend on many factors, but the etiology (origin) of any infectious disease depends on the presence of a specific pathogen. The causative agents of infectious diseases have a number of biological properties that allow them to enter the host's body, stay in it for a long time, colonize various tissues and organs and cause a specific immune response. The ability to invasiveness, colonization, persistence, toxigenicity and, as a consequence, to the emergence of an infectious disease with a certain form and course is pathogenicity. One of the most important criteria for determining the degree of pathogenicity of a microorganism is virulence - the ability of microorganisms to cause an infectious disease during experimental infection of laboratory animals. It should be noted that there is a number of known causative agents of infectious diseases in humans and animals (brucella, morbilliviruses, mycobacteria and others), the detection of which directly indicates the presence of an infectious disease. However, the presence of infectious pathologies may also be due to the presence of opportunistic microorganisms in the body. This group of pathogens is capable of causing infectious diseases only under certain conditions. For example, such conditions may include: a decrease in the level of the body's immunoreactivity under the influence of various negative factors: stress, starvation, pollution with toxicants, chronic diseases, etc.; the entry of opportunistic microorganisms into tissues and organs that are normally sterile, or there are no mechanisms of resistance to a specific type of opportunistic microorganism in these organs; with a high concentration of living microbial cells entering the internal environment of the body against the background of a decrease in the resistance of the macroorganism. In the body of healthy animals, opportunistic microorganisms may be present in small quantities in certain organs, while pathogenic factors are not manifested $[3,4,7,8]$. Consequently, detection of opportunistic microorganisms in the body of the studied individual in significant quantities, with the presence of pathogenicity factors, may indicate both a decrease in the general level of immunoreactivity of the body and presence of an infectious disease. Therefore, when studying the microbiota of the polar bear, special attention was paid not only to the species and quantitative composition of 
microbial associations, but also to the biological properties of isolated microorganisms, including the factors of their pathogenicity.

Microorganisms, as part of an ecosystem, can serve as indicators of environmental health. Thus, when studying the resistance of isolated growths of bacteria to various antibacterial drugs used in veterinary medicine and medicine, one can judge the origin of this microflora. The Arctic is a fairly isolated region for the migration of microorganisms from domestic and farm animals, as well as humans. Therefore, detection of antibiotic-resistant strains in wild animals may indicate pollution of this ecosystem with various pathogens that are not typical for this region.

\section{Materials and methods}

The material for laboratory research was obtained during complex expeditions 'KaraSummer-2014', 'Kara-Winter-2015', 'Chukotka-Summer-2015', organized by PJSC Rosneft Oil Company. Biological samples were taken from 22 polar bears for microbiological studies (Table 1). Figure 1 shows the regions and locations where this material was collected. Samples were taken from the mucous membranes of the oral cavity and conjunctiva of the eye using sterile probe-swabs. During 'Kara-Summer-2014' expedition, additional swabs were taken from the nasal cavity and anus of immobilized animals. The probe swabs with the material were placed in tubes with Ames's medium, followed by storage and transportation at a temperature of $+4{ }^{\circ} \mathrm{C}$.

Table 1. Samples of bacteriological smears from mucous membranes taken from polar bears during three complex expeditions in 2014 and 2015.

\begin{tabular}{|l|c|c|c|c|}
\hline \multirow{2}{*}{ Sampling location } & \multicolumn{3}{|c|}{ SAMPLE } & \multirow{2}{*}{ TOTAL } \\
\cline { 2 - 4 } & $\begin{array}{c}\text { Kara- } \\
\text { Summer-2014 }\end{array}$ & $\begin{array}{c}\text { Kara-Winter- } \\
2015\end{array}$ & $\begin{array}{c}\text { Chukotka- } \\
\text { Summer-2015 }\end{array}$ & 22 \\
\hline Oral cavity & 5 & 13 & 4 & 22 \\
\hline Conjunctiva & 5 & 13 & 4 & 5 \\
\hline Anus & 5 & - & - & 5 \\
\hline Nasal cavity & 5 & - & - & $\mathbf{5 4}$ \\
\hline TOTAL & 20 & 26 & 8 & \\
\hline
\end{tabular}




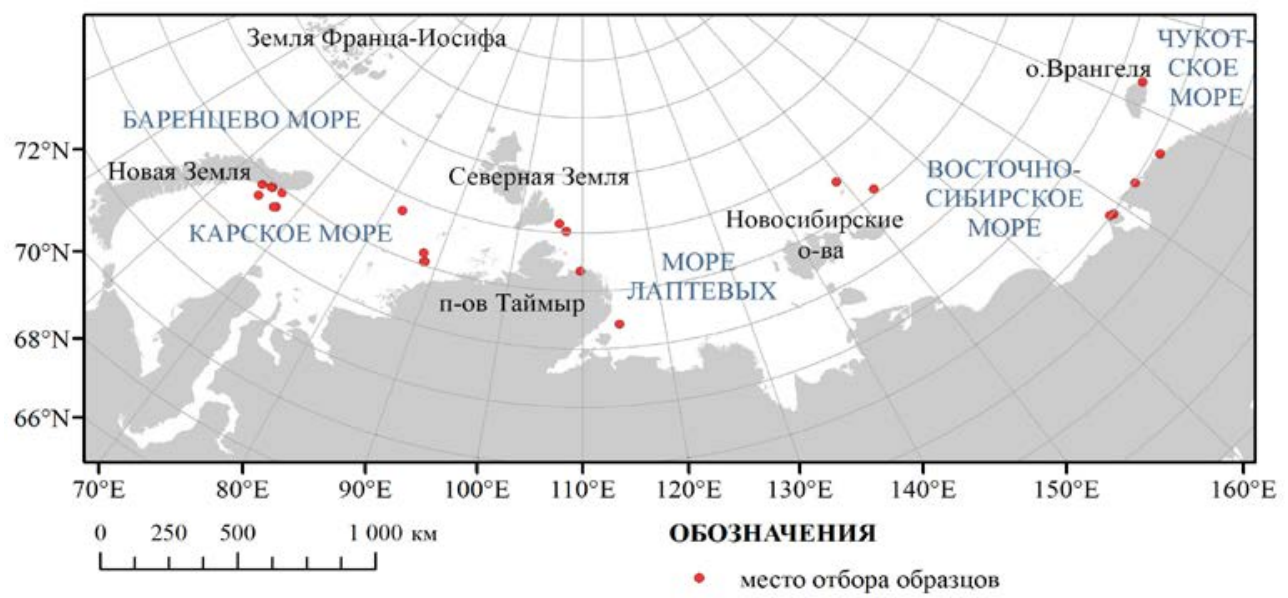

Fig. 1. Places of biological sampling from polar bears during 'Kara-Summer-2014', 'Kara-Winter2015', 'Chukotka-Summer-2015’ expeditions.

Microbiological studies of the material were carried out on basis of the Department of Microbiology of the Federal State Budgetary Educational Institution of Higher Education of the Moscow State Academy of Medical Sciences - MVA named after K.I. Scryabin, licensed to work with microorganisms of 3-4 groups of pathogenicity. A total of 54 samples was examined. Bacteriological and mycological studies of the material were carried out according to standard methods [8, 7, 3, 9] by microscopic and cultural methods. The biological properties of the isolated growths of microorganisms were studied in order to identify them $[10,11]$, as well as to assess the species and quantitative ratio in the sample. At the same time, special attention was paid to such biological properties as pathogenicity factors and resistance to antibacterial drugs. Primary inoculations of the material were made on generalpurpose and special media: blood meat-peptone agar, saline meat-peptone agar, Endo and Saburo's medium. It was cultivated at a temperature of $+37^{\circ} \mathrm{C}$ and $+24^{\circ} \mathrm{C}$ for $48-240$ hours, depending on the biological properties of microorganisms. The exactingness of some growths of isolated microorganisms to the temperature of cultivation should be noted. So, to obtain a high-quality growth of bacteria, it was required to cultivate crops for 24 hours at a temperature of $+37 \mathrm{C}$, then lower the temperature to $+20^{\circ} \mathrm{C}$ and cultivate them at this temperature from 24 to 216 hours. These biological features of the polar bear microflora were revealed for the first time and this cultivation method is planned to continue to be used in future work. The grown colonies of microorganisms were viewed with the naked eye and using a microscope or a magnifying glass (10x magnification). The total number of CFU (colony-forming units - living cells of microorganisms capable of forming separate colonies on a dense nutrient medium), as well as the number of colonies of various morphological groups, were calculated, followed by their identification. The isolates were identified by morphology, tinctorial, cultural, enzymatic properties, and antigenic structure. The enzymatic activity was studied using the 'Micro-la-test' kits by Lahema: Stafitest 24, Enterotest 24, Nefermtest 24 and additional tests: sensitivity to bacitracin, neomycin; VogesProskauer reaction, pirate, oxytest. The study of pathogenicity factors was carried out by studying hemolytic properties, the presence of plasma coagulase, lecithinase, as well as virulence during experimental infection of white mice.

To determine the origin of bacterial isolates isolated from polar bears, we studied sensitivity of these microorganisms to antibacterial drugs used to treat infectious diseases in medical and veterinary practice [12]. The sensitivity test was performed using the standard 
disc method. The sensitivity of microflora to the following drugs was investigated: Cefixime, Penicillin, Ciprfloxacin, Cefazolin, Levofloxacin, Amikacin, Cefepim, Levomecitin, Bacitracin, Lincomycin, Sulfanilamide, Erythromycin, Gentamicin, Oxacillin, Merlokopenamicin, Streptococcus, Ofenampicin The results were evaluated by measuring the diameter of the sterile zone around the antibiotic disc - growth retardation zone (GRZ).

\section{Results}

As a result of the studies carried out, microorganisms of various types were found in $78.2 \%$ of the samples (Table 2).

Table 2. The total number and species composition of isolated pure growths of microorganisms from the oral cavity and conjunctiva of the polar bear's eye

\begin{tabular}{|c|c|c|c|}
\hline $\begin{array}{l}\text { Specific or generic name of the } \\
\text { microorganism }\end{array}$ & $\begin{array}{l}\text { Total } \\
\text { number of } \\
\text { isolates } \\
\text { obtained }\end{array}$ & $\begin{array}{l}\text { Percentage of } \\
\text { the total } \\
\text { number of } \\
\text { isolates (\%) }\end{array}$ & $\begin{array}{l}\text { Sample where the } \\
\text { microorganism was found } \\
\text { (name of the expedition) * }\end{array}$ \\
\hline E.coli & 9 & 9.9 & KS, KW \\
\hline Enterobacter aerogenes & 2 & 2.2 & KS \\
\hline Proteus vulgaris & 2 & 2.2 & KS \\
\hline Aeromonas & 11 & 12.5 & KS, KW, ChS \\
\hline Staphylococcus epidermidis & 6 & 6.6 & KS, ChS \\
\hline Staphylococcus hyicus & 7 & 7.7 & KS, KW \\
\hline Staphylococcus aureus & 2 & 2.2 & KS \\
\hline Streptococcus canis & 1 & 1.1 & KS \\
\hline Bacillus & 7 & 7.7 & KS, KW, ChS \\
\hline Candida albicans & 14 & 15.9 & $\mathrm{KS}, \mathrm{KW}, \mathrm{ChS}$ \\
\hline Enterococcus faecalis & 3 & 3.3 & KS \\
\hline Serratia marcescens & 3 & 3.3 & KW \\
\hline Dermococcus nishinomiyaensis & 7 & 7.7 & KS, ChS \\
\hline Moraxella & 1 & 1.1 & KW \\
\hline Staphylococcus kloosii & 2 & 2.2 & KW, ChS \\
\hline Providencia rustigianii & 1 & 1.1 & KW \\
\hline Citrobacter gillenii & 1 & 1.1 & KW \\
\hline $\begin{array}{l}\text { Staphylococcus cohnii ssp. } \\
\text { urealyticum }\end{array}$ & 3 & 3.3 & ChS \\
\hline
\end{tabular}




\begin{tabular}{|l|c|c|c|}
\hline $\begin{array}{l}\text { Staphylococcus shleiferi ssp. } \\
\text { shleiferi }\end{array}$ & 2 & 2.2 & ChS \\
\hline Yersinia frederiksenii & 3 & 3.3 & $\mathrm{ChS}$ \\
\hline Pantonea dispersa & 1 & 1.1 & $\mathrm{ChS}$ \\
\hline Trichophyton & 1 & 1.1 & $\mathrm{ChS}$ \\
\hline Aspergillus & 1 & 1.1 & \\
\hline TOTAL: & 91 & 100 & \\
\hline
\end{tabular}

* Designations in the table: KS - 'Kara-Summer-2014'; KW - 'Kara-Winter-2015'; ChS - 'ChukotkaSummer-2015,

From the material of the mucous membranes of the oral cavity and conjunctiva of the eye of all the studied individuals of the polar bear, 91 isolates of microorganisms were obtained, identified up to 23 genera and species (Table 2). These microorganisms were represented by both bacteria and microscopic fungi. At the same time, the data obtained in the study of the material selected in different expeditions differed. Thus, it was noted that $100 \%$ of the samples obtained during 'Kara-Summer-2014' expedition contained various microorganisms with a significant predominance of bacteria of the genus Staphylococcus. A total of 49 growths of microorganisms were obtained from 5 animals, from the conjunctiva of the eye and from the oral cavity - 28 growths. In samples collected from 14 animals during 'KaraWinter-2015' expedition, the growth of bacteria and fungi was noted only in $59.3 \%$ of the material. In this case, the predominant microorganisms were Enterobacteriaceae. A total of 37 isolates were obtained. When studying material taken from 4 polar bears during 'Chukotka-Summer-2015' expedition, the growth of microorganisms was observed in $87.5 \%$ of the crops. The predominant microorganisms were Staphylococci. A total of 26 growths of bacteria and fungi were obtained.

Despite the fact that in the material obtained from animals during 'Kara-Summer2014' and 'Chukotka-Summer-2015' expeditions bacteria of the genus Staphylococcus predominated, they differed significantly in species composition. Thus, from the samples of 2014 selection, we isolated S. hyicus, S. epidermidis, S. aureus, and in Chukchi bears - S. cohnii ssp. urealyticum, S. epidermidis, S. shleiferi ssp. shleiferi, S. kloosii. Only S. epidermidis was found to be a common species. In the material collected in the spring of 2015 ('Kara-Summer-2015') from 14 animals, Staphylococci were also present, but their number was several times less than in other studied groups of bears. Staphylococci of this group of animals were represented by the following species: S. kloosii and S. hyicus.

When studying the total contamination of samples, the number of living microorganisms in them, as well as the number of species of bacteria and fungi, it turned out that the highest CFU was in samples from the oral cavity of animals from the 'ChukotkaSummer-2015' sample and amounted to $10.5 \times 10^{3}$. In the material selected during 'KaraWinter-2015' expedition from 14 animals mainly showed a poor growth of microorganisms (CFU less than $0.01 \times 10^{3}$ ). [10]

Associations of the isolated microorganisms in 9 polar bears were represented by five or more species of microorganisms, while monogrowths and dyads were found singularly (Figure 2). 


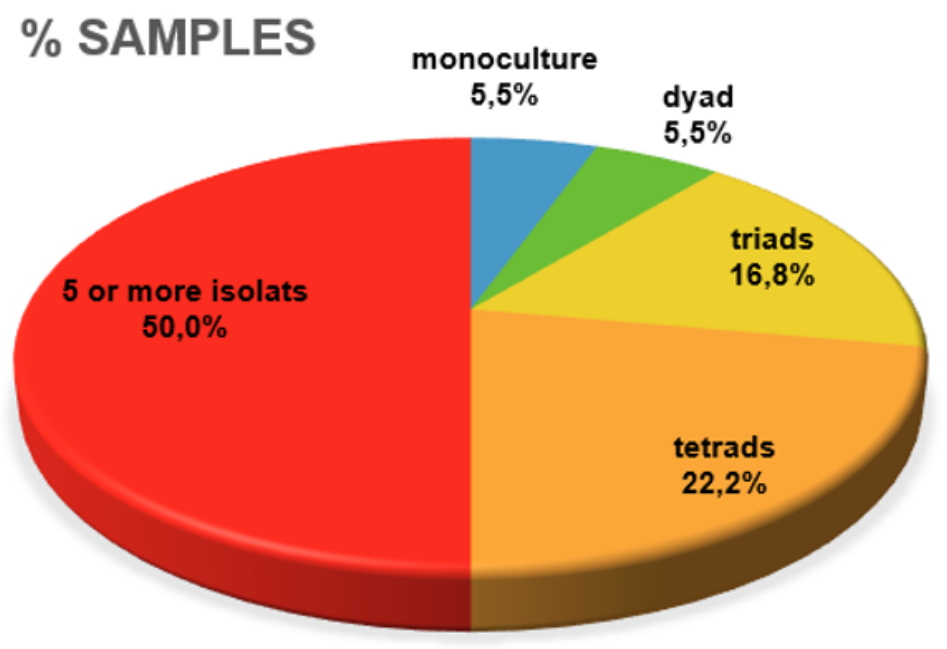

Fig. 2. Frequency of isolation of microorganisms from material in pure growth and in various associations

We also noted significant differences when studying the species composition of microorganisms in the conjunctiva of the eye and oral cavity. The microflora of the polar bear's oral cavity was distinguished by the greatest species diversity and the total number of living cells.

One or more signs of pathogenicity were identified in 31 isolated growths of microorganisms (Table 3). The rest of the isolates, including non-pathogenic staphylococci, did not show hemolytic properties, did not detect the presence of plasmokoagulase, lecithinase, and were avirulent for white mice.

Table 3. Proportion (\%) of isolates of isolated growths of microorganisms with a positive trait

\begin{tabular}{|l|c|c|c|c|}
\hline Microorganisms & \multicolumn{3}{|c|}{ Pathogenic factors } \\
\hline & Hemolysin & $\begin{array}{l}\text { Plasma } \\
\text { coagulase }\end{array}$ & Lecithinase & Virulence \\
\hline E.coli $n=9$ & 55.6 & 0 & 0 & 0 \\
\hline $\begin{array}{l}\text { Staphylococcus epidermidis } \\
n=6\end{array}$ & 67 & 16 & 50 & 0 \\
\hline $\begin{array}{l}\text { Staphylococcus hyicus } \\
n=7\end{array}$ & 100 & 100 & 100 & 0 \\
\hline $\begin{array}{l}\text { Staphylococcus aureus } \\
n=2\end{array}$ & 100 & 100 & 100 & 0 \\
\hline $\begin{array}{l}\text { Dermococcus nishinomiyaensis } \\
n=7\end{array}$ & 43 & 0 & 14.3 & 0 \\
\hline $\begin{array}{l}\text { Staphylococcus kloosii } \\
n=2\end{array}$ & 100 & 50 & 0 & 0 \\
\hline
\end{tabular}




\begin{tabular}{|l|c|c|c|c|}
\hline Microorganisms & \multicolumn{3}{|c|}{ Pathogenic factors } \\
\hline $\begin{array}{l}\text { Staphylococcus cohnii ssp. } \\
\text { urealyticum } n=3\end{array}$ & 66.6 & 33.3 & 0 & 0 \\
\hline $\begin{array}{l}\text { Staphylococcus shleiferi ssp. } \\
\text { shleiferi } n=2\end{array}$ & 50 & 0 & 50 & 0 \\
\hline $\begin{array}{l}\text { Yersinia frederiksenii } \\
n=3\end{array}$ & 100 & 0 & 33.3 & 33.3 \\
\hline
\end{tabular}

When studying virulence of isolated growths for white mice, 30 isolates of microorganisms were found to be avirulent during experimental infection. As a result of infection with the culture of Yersinia frederiksenii isolated from the conjunctiva of the eye of one animal, the death of white mice was noted 148 hours after infection.

When studying the etiological role of microflora isolated from the studied individuals of polar bears, special attention was paid to bacteria of the genus Staphylococcus, since these microorganisms are often causative agents of purulent-septic diseases in animals of different species and in humans. Most often, staphylococcosis in humans, marine mammals and predators is caused by S. aureus [7]; in many species of farm animals - S. epidermidis [3]; in cetaceans - S. delphini [3]; in dogs - S. hyicus, S. intermedius [3]. However, these microorganisms can also be normal inhabitants of the skin, mucous membranes, mouth and upper respiratory tract. In the case of a decrease in the level of immunoreactivity of the body, staphylococci can cause severe pathologies that can be fatal. The types of staphylococci we isolated from a polar bear in the Chukotka region are conditionally pathogenic microorganisms. The literature describes cases of human disease caused by the species $\mathrm{S}$. kloosi, S. cohnii, S. shleiferi, but, as a rule, in the presence of immunosuppression or immunodeficiencies, or as opportunistic infections [7]. Data on the pathologies caused by these types of staphylococci in wild predators were not found. At the same time, the presence of pathogenicity factors in the staphylococci isolated by us allows us to consider them as a possible etiological factor in the occurrence of infectious pathologies (diseases) in polar bears in the event of a decrease in the level of immunoreactivity of the organism.

Yersinia frederiksenii is one of the causative agents of yersiniosis in animals, some species of fish and humans, which can manifest as gastroenterocolitis, arthritis, conjunctivitis, dermatitis and bronchopneumonia. However, latent microbearer is more often noted, in which microorganisms are excreted in feces and can enter the environment, where they are well preserved.

When studying the antibiotic resistance of microflora isolated from polar bears, it was found that growths of microorganisms showed high sensitivity to many antibacterial drugs, with the exception of species resistance. Sensitivity to such modern, frequently used antibiotics as ciprofloxacin, amikacin, levofloxacin, gentamicin may indicate that the majority of bacteria isolated in the course of these studies are autochthonous (resident microorganisms that live in a given ecosystem since its formation and which have not acquired resistance to drugs used in the tests). However, the medium and high degree of resistance to ciprofloxacin and cefazolin of bacteria of the genus Yersinia should be noted, which may indirectly indicate the anthropogenic origin of these microorganisms. Considering the fact that Yersinia spp. are very well preserved in the environment and can even multiply at low above-zero temperatures, it can be assumed that these microorganisms got into the body of bears when they came into contact with the products of human economic activity: garbage, sewage, etc. 
Thus, the microflora of each investigated individual of the polar bear has characteristics in terms of the composition and properties of its constituent microorganisms. To characterize these features, the so-called microbiological status is determined for each surveyed polar bear, reflecting the quantitative and qualitative parameters of microbial associations. The quantitative parameter is $\mathrm{CFU}$, and the qualitative parameter is the manifestation of pathogenic properties by this microflora.

The study of the microbiological status of animals makes it possible to significantly supplement the results of biological studies of the polar bear population in the Russian Arctic and, along with clinical veterinary examinations and toxicological analysis, to determine the health status of individuals.

An important promising task is to increase the sample both by region and by seasons of collection of samples, as well as by sex and age composition of polar bears. Thus, the background indicators of the microbiological status of polar bears can be identified depending on the season and region, which, in turn, will serve as an important component for monitoring the state of ecosystems by tracking the state of the main Arctic predator.

This line of research is becoming especially relevant in the current century, when economic and other activities cover all new regions of the Arctic. Against the background of a warming climate, this activity can provoke the emergence of new microorganisms with pathogenic properties. Considering this, the polar bear range countries, which approved the Circumpolar Action Plan for the Conservation of the Polar Bear in September 2015 in Illullisat (Greenland), highlighted the importance of monitoring their health status as one of the indicators of the species' response to changes in its natural habitat under the action of anthropogenic factors.

\section{References}

1. Order of the Ministry of Natural Resources of Russia No. 25-p dated September 22, 2015 'On approval of the list of flora and fauna species that are indicators of the sustainable state of marine ecosystems in the Arctic zone of the Russian Federation' (2015).

2. E.V. Ivanter, N.V. Medvedev. Ecological toxicology of natural populations of birds and mammals of the North; Institute of forests, KarRC RAS. - M.: Nauka, (2007) -229 p.

3. D.I. Skorodumov, V.V. Subbotin, M.A. Sidorov, T.S. Kostenko. Handbook: 'Microbiological diagnostics of bacterial diseases of animals', M.: Izograf, (2005) - 653 p.

4. L.A Dierauf, F.M.D. Gulland «Handbook of marine mammal medicine: health, disease, veterinary medicine and wildlife rehabilitation» $\left(2^{\text {nd }}\right.$ ed.), - CRC Press LLC, (2001), $1063 \mathrm{p}$.

5. T. Glad, P. Bernhardsen, K.M. Nielsen, L Brusetti, M Andersen, J Aars, MA Sundset Bacterial diversity in faeces from polar bear (Ursus maritimus) in Arctic Svalbard. BMC Microbiology 10 (2010).

6. C Schwab, M Gänzle Comparative analysis of fecal microbiota and intestinal microbial metabolic activity in captive polar bears. Can J Microbiol. 57 (2011) pp.177-185.

7. V.I. Pokrovsky, O.K. Pozdeev. Medical Microbiology - M.: GOETAR MEDICINE, (1998). -1200 p.

8. B.I. Antonov, T.F. Yakovleva, V.I. Derbinova Laboratory research in veterinary medicine: biochemical and mycological. - M.: Agropromizdat. - (1989). -324 p.

9. P.N. Costillow «Manual of methods for General Bacteriology» (1981), v.1. 185 p.

10. Edited by J. Hoult, N. Krieg, P. Sneet, J. Staley, S. Williams. Burgey’s keys to bacteria. Ninth Edition. M.: Mir, (1997) - 799 p. 
11. D. Sutton, A. Fothergill, M. Rinaldi. Keys to pathogenic and opportunistic fungi: Transl. from English - M.: Mir, (2001). - 486 p.

12. M.A. Gilliver, M. Bennett, M. Begon, S.M. Hazel, C.A. Hart: Enterobacteria: Antibiotic resistance found in wild rodents. Nature (1999), 401(6750): 233-234 p. 